\title{
An overview of the sexual and reproductive health status and service delivery among Syrian refugees in Jordan, nine years since the crisis: a systematic literature review
}

\author{
Mirwais Amiri ${ }^{1 *}$ (D, leman M. El-Mowafi ${ }^{2}$, Tala Chahien ${ }^{1}$, Hind Yousef ${ }^{1}$ and Loulou Hassan Kobeissi ${ }^{3}$
}

\begin{abstract}
Background: The Syrian refugee crisis has led to massive displacement into neighboring countries including Jordan. This crisis has caused a significant strain on the sexual and reproductive health (SRH) services to the host communities and Syrian refugees. The Minimum Initial Service Package (MISP) is a standard package of services that should be implemented at the onset of an emergency. Due to their importance in protracted humanitarian crisis, this systematic review aimed to assess the utilization of SRH and MISP after 9 years of the crisis.

Methods: We searched PubMed, Medline/Ovid and Scopus for both quantitative and qualitative studies from 1 January 2011 to 30 November 2019. Our search included both free text key words and Medical Subject Headings (MeSH) for various forms and acronmym of the following terms: (Sexual and) Reproductive Health, Sexual/Genderbased/Family/Intimate partner violence, Minimum Initial Service Package, MISP, Women, Girls, Adolescents, Syrian, Refugee, Jordan, Humanitarian crisis, War, (armed) conflict, and Disaster. Boolean operators and star truncation (*) were used as needed. We further conducted an in-depth review of the available grey literature published during the same timeframe. Using a narrative synthesis approach, two authors independently extracted and analyzed data from published papers. After removal of duplicates, screening, and assessing for eligibility of 161 initially identified citations, 19 papers were selected for review.

Results: Findings from this review indicated a number of barriers to access, utilization, and implementation of SRH services, including lack of reliable information on sexual and gender-based violence (SGBV), aggravation of early marriages by crisis setting, gaps in the knowledge and use of family planning services, inadequate STIs and HIV coverage, and some issues around the provision of maternal health services.

(Continued on next page)
\end{abstract}

\footnotetext{
*Correspondence: mamiri@globalhealthdev.org; mamiri@alumni.emory.edu

${ }^{1}$ The Eastern Mediterranean Public Health Network (EMPHNET), Shmeisani,

Abdallah Ben Abbas Street, Bldg No. 42, Amman, Jordan

Full list of author information is available at the end of the article
}

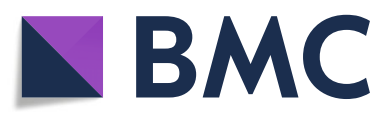

(c) The Author(s). 2020 Open Access This article is licensed under a Creative Commons Attribution 4.0 International License, which permits use, sharing, adaptation, distribution and reproduction in any medium or format, as long as you give appropriate credit to the original author(s) and the source, provide a link to the Creative Commons licence, and indicate if changes were made. The images or other third party material in this article are included in the article's Creative Commons licence, unless indicated otherwise in a credit line to the material. If material is not included in the article's Creative Commons licence and your intended use is not permitted by statutory regulation or exceeds the permitted use, you will need to obtain permission directly from the copyright holder. To view a copy of this licence, visit http://creativecommons.org/licenses/by/4.0/. The Creative Commons Public Domain Dedication waiver (http://creativecommons.org/publicdomain/zero/1.0/) applies to the data made available in this article, unless otherwise stated in a credit line to the data. 


\begin{abstract}
(Continued from previous page)
Conclusion: The findings from this review are suggestive of a number of barriers pertaining to access, utilization, and implementation of SRH services. This is especially true for transitioning from MISP to comprehensive SRH services, and particularly for refugees outside camps. Following are needed to address identified barriers: improved inter-agency coordination, better inclusion/engagement of local initiatives and civil societies in SRH services delivery, improved quality of SRH services, adequate and regular training of healthcare providers, and increased awareness of Syrian women and adolescent girls. Also, more implementing research is required to identify ways to transition SRH provision from the MISP to comprehensive care for the Syrian refugee population in Jordan.
\end{abstract}

Keywords: Sexual and reproductive health, Reproductive health, Sexual violence, Family violence, Intimate partner violence, Gender-based violence, Minimum initial service package, Syrian refugees, Syrian crisis, Humanitarian settings

\section{Plain English summary}

In order to understand better the sexual and reproductive health (SRH) needs of Syrian refugees, our study team aimed to review all published papers and available reports in an attempt to reduce research waste.

The purpose of this review is to examine the available published literature on the provision of SRH services for Syrian refugees in Jordan. We specifically aimed to identify and describe the current SRH issues and challenges faced by Syrian refugees in Jordan. We sought to understand better about service delivery in Jordan for Syrian refugees, its ability to transition to comprehensive SRH services, and highlight prevailing bottlenecks and opportunities impacting this transition. Therefore, we aimed to conduct a scoping review to systematically search databases for published articles.

Our findings indicate that Syrian refugee women face multi-faceted barriers to access and uptake of SRH services. These barriers include lack of reliable information on sexual and gender-based violence (SGBV), aggravation of early marriages by crisis setting, gaps in the knowledge and use of family planning services, inadequate STI and HIV coverage, and issues around the provision of maternal health services. The following are needed to address identified barriers: improved interagency coordination, better inclusion/engagement of local initiatives and civil societies in SRH services delivery, improved quality of SRH services, adequate and regular training of healthcare providers, and increased awareness of Syrian women and adolescent girls.

\section{Background}

The Syrian crisis has resulted in one of the worst humanitarian disasters in modern history. Since 2011, the crisis had led to over 13 million people requiring humanitarian assistance; more than 11 million Syrians are currently internally displaced or have sought refuge into neighboring countries; half of whom are women and girls of reproductive age. The United Nations High
Commission for Refugees (UNHCR) estimates that over one million people from Syria currently reside in Jordan, including approximately 650,000 Syrian refugees registered with UNHCR $[1,2]$, and as many as 700,000 unregistered individuals who are unable to return to Syria [2]. The overwhelming majority of Syrian refugees in Jordan live in rural and urban areas across the country; indeed, only $21 \%$ of Syrian refugees live in camp-based settings. As a result, Syrians who live in these disparate communities must rely on local health services [3]. Evidence suggests that the influx of refugees has placed an unsustainable strain on schools, housing, sanitation, food and the health care systems in Jordan [4]. Further, it is estimated that $86 \%$ of Syrian refugees are currently living under the Jordanian poverty line and $75 \%$ are considered highly shelter vulnerable [5]. The inequitable distribution of poverty, employment opportunities, and educational attainment, which are further exacerbated by displacement, impacts individuals and communities' access to health services and health outcomes [6].

A body of evidence shows that Syrian refugee women and girls have significant unmet sexual and reproductive health (SRH) needs in comparison to their host community counterparts [7]. According to the 2018 Jordan's Population and Family Health Survey (JPFHS), Syrian refugee women have a total fertility rate (TFR) of 4.7 versus 2.6 children per women among Jordanian women [8]. Further, several recent studies suggest that Syrian refugee women and girls experience high rates of sexual violence and early and forced marriage, have more difficulty accessing family planning services and in turn experience higher rates of unintended and unwanted pregnancy $[7,9,10]$. Consistent with global trends, displacement has resulted in many families facing the loss of livelihood, security and the protection provided by their families and communities. This financial and protection insecurity has resulted in families marrying their daughters at younger ages [10]. Indeed, the early marriage rates among Syrian girls between the ages of 15-17 
has increased by threefold since the civil war [11, 12]. Moreover, evidence suggests that these girls' husbands are often the primary decision makers regarding family formation, impacting their access to comprehensive SRH services [10].

Research conducted in refugee camps indicate that women and adolescents are at increased risk of physical and sexual violence and rape [13]. Findings from recent studies suggest that women and girls face harassment from both humanitarian workers and men from their community, especially during instances when women and adolescents need to travel to remote areas to purchase food and water and/or access open toilets [13, 14]. Further, a study conducted by UNWomen exploring intimate partner violence (IPV) in Jordan found that Syrian refugee women and girls are more likely to experience a form of IPV, mainly intra-family violence, in comparison to their Jordanian counterparts [10].

During the onset of the crisis in 2011, Syrian refugees in Jordan benefited from free public health services. However, this changed between 2012 to 2014, as they were required to show both their local service card and the UNHCR registration to get free access to health care. From November 2014, free health care was rescinded for Syrian refugees, but they still received the same subsidies as uninsured Jordanians. Finally, as of January 2018, the government revoked access to subsidized health care for all Syrian refugees residing outside of refugee camps [15]. The primary and secondary health care for Syrian refugees, residing in the camps, are still fully covered by the UNHCR. However, the majority of refuges are unfortunately not insured and therefore have to pay healthrelated fees for hospitals and clinics [16].

As estimated by UNFPA in 2015, as a result of inadequate international funding, 70,000 pregnant Syrian women had given birth in unsafe conditions due to inadequate access to maternal health services [17] and skilled birth attendants during delivery. A proportion of these women include Syrian refugee women in Jordan. Although the SRH needs of displaced and refugee populations have increased globally, funding for such programming has decreased over the last few years. For example, UNFPA in 2015 received less than half the funding it required to meet the essential SRH needs of women and adolescents [18]. This has important implications on the quality and capacity of the SRH humanitarian response and service delivery [14]. Given this context, it is evident that there still remains significant need for SRH service delivery for Syrian refugees in Jordan. The Minimum Initial Service Package (MISP) is a series of crucial actions required to respond to $\mathrm{RH}$ needs at the onset of every humanitarian crisis. The MISP is not solely kits of equipment and supplies; it is a set of objectives and activities that must be implemented in a coordinated manner by appropriately trained staff. This set of life-saving activities forms the starting point for ensuring quality $\mathrm{RH}$ service delivery in even the worst scenarios. These actions should be sustained and expanded with comprehensive $\mathrm{RH}$ services throughout protracted crises and recovery (See Table 1).

Almost 9 years into the crisis, available documentation on the MISP implementation in Jordan and the transitioning from MISP to comprehensive SRH services is minimal and limited. The Syrian crisis has caused a widespread deterioration of the public health system, encompassing a decline in the number of health professionals and facilities to meet the needs of the host as well as the refugee population in Jordan [19]. While the evidence on the effectiveness of SRH interventions is extensive, the gaps still needed to be examined to explore why such shift of SRH interventions to comprehensive services did not happen in Jordan. Thus, it is essential to examine evidence on the effectiveness of SRH interventions in Jordan to identify gaps and provide policy briefs to decision makers that will contribute to improving SRH service delivery to both refugee and host communities.

This systematic review aims to 1) examine available published literature on the provision of the MISP for Syrian refugees in Jordan; 2) to describe and identify the current SRH issues and challenges experienced by Syrian refugee (with particular emphasis on women and girls) in Jordan; and 3) to reflect on the quality of service delivery, ability to transition to comprehensive SRH services, as well as reflect prevailing bottlenecks and opportunities impacting such transition.

\section{Methods}

This review adopted the systematic review procedures by Khan, Kunz, Kleijnen, \& Antes [20]. As the first step, the research question was stated as a free form query, which informed the three aims described above. In the second step, a search strategy was formulated using combination of search terms with Boolean operators to conduct an extensive search of multiple resources (research databases) to identify relevant work. The identified citations were narrowed down by inclusion and exclusion criteria (as provided in Table 2). In the third step, selected studies were further assessed for their quality and to explore and ensure heterogeneity of the findings. In the fourth step, collected evidence were synthesized summarized (see Table 3).

Search terms for SRH were based on the standardized definitions from the International Conference on Population and Development in 1994 as well as the revised 2018 IAFM (Inter-Agency Field Manual) objectives described above [21]. Sexual and reproductive health (SRH) refers to the "constellation of methods, techniques 
Table 1 Minimum Initial Service Package (MISP) Objectives and Activities

\section{Ensure the health sector/cluster identifies an organization to lead implementation of the MISP. The lead SRH organization:}

- Nominates an SRH Coordinator to provide technical and operational support to all agencies providing health services

- Hosts regular meetings with all relevant stakeholders to facilitate coordinated action to ensure implementation of the MISP

- Reports back to the health cluster, GBV sub-cluster, and/or HIV national coordination meetings on any issues related to MISP implementation.

- In tandem with health/GBV/HIV coordination mechanisms ensures mapping and analysis of existing SRH services

- Shares information about the availability of SRH services and commodities

- Ensures the community is aware of the availability and location of reproductive health services

\section{Prevent sexual violence and respond to the needs of survivors:}

- Work with other clusters especially the protection or gender-based violence sub-cluster to put in place preventative measures at community, local, and district levels including health facilities to protect affected populations, particularly women and girls, from sexual violence

- Make clinical care and referral to other supportive services available for survivors of sexual violence

- Put in place confidential and safe spaces within the health facilities to receive and provide survivors of sexual violence with appropriate clinical care and referral

3. Prevent the transmission of and reduce morbidity and mortality due to HIV and other STIs:

- Establish safe and rational use of blood transfusion

- Ensure application of standard precautions

- Guarantee the availability of free lubricated male condoms and, where applicable (e.g., already used by the population), ensure provision of female condoms

- Support the provision of antiretrovirals (ARVs) to continue treatment for people who were enrolled in an anti-retroviral therapy (ART) program prior to the emergency, including women who were enrolled in PMTCT programs

- Provide PEP to survivors of sexual violence as appropriate and for occupational exposure

- Support the provision of co-trimoxazole prophylaxis for opportunistic infections for patients found to have HIV or already diagnosed with HIV

- Ensure the availability in health facilities of syndromic diagnosis and treatment of STIs

4. Prevent Excess maternal and newborn morbidity and mortality:

- Ensure availability and accessibility of clean and safe delivery, essential newborn care, and lifesaving emergency obstetric and newborn care (EmONC) services including:

- At referral hospital level: Skilled medical staff and supplies for provision of comprehensive emergency obstetric and newborn care (CEmONC) to manage

- At health facility level: Skilled birth attendants and supplies for uncomplicated vaginal births and provision of basic obstetric and newborn care (BEmONC)

- At community level: Provision of information to the community about the availability of safe delivery and EmONC services and the importance of seeking care from health facilities. Clean delivery kits should be provided to visibly pregnant women and birth attendants to promote clean home deliveries when access to a health facility is not possible

- Establish a $24 \mathrm{~h}$ per day 7 days per week referral system to facilitate transport and communication from the community to the health center and hospital

- Ensure the availability of life saving post-abortion care in health centers and hospitals

- Ensure availability of supplies and commodities for clean delivery and immediate newborn care where access to a health facility is not possible or unreliable

\section{Prevent unintended pregnancies:}

- Ensure availability of a range of long-acting reversible and short-acting contraceptive methods (including male and female condoms and emergency contraception) at primary health care facilities to meet demand

- Provide information, including existing information, education, and communications (IEC) materials, and contraceptive counseling that emphasizes informed choice and consent, effectiveness, client privacy and confidentiality, equity, and non-discrimination

- Ensure the community is aware of the availability of contraceptives for women, adolescents, and men

Plan for comprehensive SRH services:

- Integrated into primary health care as soon as possible.

- Work with the health sector/cluster partners to address the six-health system building blocks: service delivery; health workforce; health information system; medical commodities; financing; and, governance and leadership.

Note: It is also important to ensure that safe abortion care is available, to the full extent of the law, in health centers and hospital facilities

and services that contribute to reproductive health $(\mathrm{RH})$ and well-being by preventing and solving RH problems". These SRH and MISP terms were carefully explored in order to ensure that no literature has been unintentionally omitted and to ensure the search is as comprehensive and up to date as possible.

For the purpose of this systematic review, a humanitarian crisis is defined as a serious disruption of the functioning of a community or a society causing widespread human, material, economic or environmental losses which exceeds the ability of the affected community/society to cope with its own resources, thus necessitating a request to national and international aid and assistants [22].

This review included both peer-reviewed articles and grey literature reports. The dates of publications were restricted to 1 January 2011-30 November 2019. We searched for peer-review published literature across three databases: PubMed, Medline (Ovid), and Scopus. For the grey literature, websites of the leading international agencies providing humanitarian support were explored, such as: United Nations Population Fund (UNFPA), GirlsnotBrides, Raise Initiative, Inter-Agency Working Group on Reproductive Health in Crises 
Table 2 Inclusion and exclusion criteria

\begin{tabular}{lll}
\hline Category & Included & Excluded \\
\hline Population of interest & $\begin{array}{l}\text { Crisis-affected populations receiving MISP, general SRH } \\
\text { services and interventions in humanitarian contexts } \\
\text { (as defined by IAWG), specifically refugee and internally }\end{array}$ & Studies that did not include Syrian populations \\
& displaced persons. Within the definition, this population \\
& was further limited to Syrian refugees in Jordan. & \\
Health outcomes or Outputs & Primary outcomes (Prevent SV, changes in maternal & Studies which did not quantify the MISP and/or \\
& mortality and morbidity rates from HIV, STI prevention, & SRH-related health indicators. \\
& GBV, and other SRH areas) Secondary outcomes & \\
& (Respond to needs of SV and GBV survivors, prevent & \\
unintended pregnancy through contraceptive use) & \\
Intervention & Any provision of the SRH services included in MISP, & \\
not only if they were provided as part of a MISP & \\
intervention & Non-empirical work, such as commentaries and \\
Humanitarian crisis & Studies included during the onset of a crisis, emergency, \\
chronic, and early recovery phases of the crisis & had not undergone peer-review, such as \\
Reports of findings by organizations involved in & \\
humanitarian contexts & \\
Study types and Designs & All qualitative study designs or mixed methods & \\
Publication date & February 2011 to May 2019 & \\
Language & English & Other languages \\
\hline $\begin{array}{l}\text { Abbreviations: } M I S P \text { minimum initial service package, IAWG inter-agency working group, STI sexually transmitted infection, SV sexual violence, GBV gender-based } \\
\text { violence, SRH sexual reproductive health }\end{array}$
\end{tabular}

(IAWG), Save the children, the International Rescue Committee (IRC), CARE, International Committee of the Red Cross (ICRC), International Planned Parenthood Federation (IPPF) and UNWomen. Google search engine was used to identify relevant literature and reports not published in peer-reviewed journals. Further, the search was supplemented by screening the references cited by the eligibly included papers to identify potentially missed peer-reviewed articles.

Electronic databases were searched for both free text key words and Medical Subject Headings (MeSH) to identify all relevant terms. Boolean operator 'OR' was used to widen search to include free text keywords and $\mathrm{MeSH}$ terms defining the same concepts, while 'AND' was used to narrow down the search by combining different concepts into the search strategy and arrive at the final search results.

We used key search terms ('Sexual and Reproductive Health' OR 'SRH' OR 'Reproductive Health' OR 'RH' OR 'Sexual Violence' OR 'Family violence' OR Intimate partner violence' OR 'IPV' OR '(Sexual and) Gender-based Violence', OR '(S)GBV', OR 'Minimum Initial Service Package', OR 'MISP'), AND ('Women', OR 'Girls', OR 'Adolescents'), AND ('Syrian' OR 'Refugee', OR 'Jordan'), AND ('Humanitarian crisis', OR 'War', OR '(Armed) conflict' OR 'Crisis' OR 'Disaster'). Further, we used star truncation $\left(^{*}\right)$, as needed, to account for multiple endings of terms, such as "Adolescent" for adolescent, adolescents, and adolescence. We also applied search filters to limit published article and reports between 2011- 2019 .
Inclusion and exclusion criteria were based on the Inter-Agency Field Manual (IAFM) on reproductive health in humanitarian settings [23]; these are outlined in Table 2.

Two researchers independently downloaded all identified citations into a Mendeley library, and each assessor applied the standard data-screening process as shown in the PRISMA flow chart [33] in Fig. 1. Initially, 161 records were identified: 149 through the research databases and 12 through other sources (grey literature). A total of 102 records were excluded as duplicates, leaving us with 59 records. In the screening stage, the titles and abstracts for all 59 records were reviewed. A total of 26 more records were excluded, because they either had irrelevant titles and abstract or they were commentaries or editorials. Thus, a total of 33 full-text articles or reports were included to be assessed against eligibility criteria (see Table 2). During this stage, 14 full-text articles or reports were excluded: 4 were excluded because they were not MISP or SRH interventions; and 10 were excluded for not meeting other inclusion criteria. Finally, a total of 19 papers (published articles or reports) were included in our qualitative synthesis, as shown in the PRIS MA flow chart below. Following the title, abstract and full text screening and review, the needed information from the selected studies and reports were extracted into an Excel database (available as a table at the 'Results' section of this paper and as a separate Excel sheet). The extraction focused on the following data: study design and methods, participant characteristics, research 


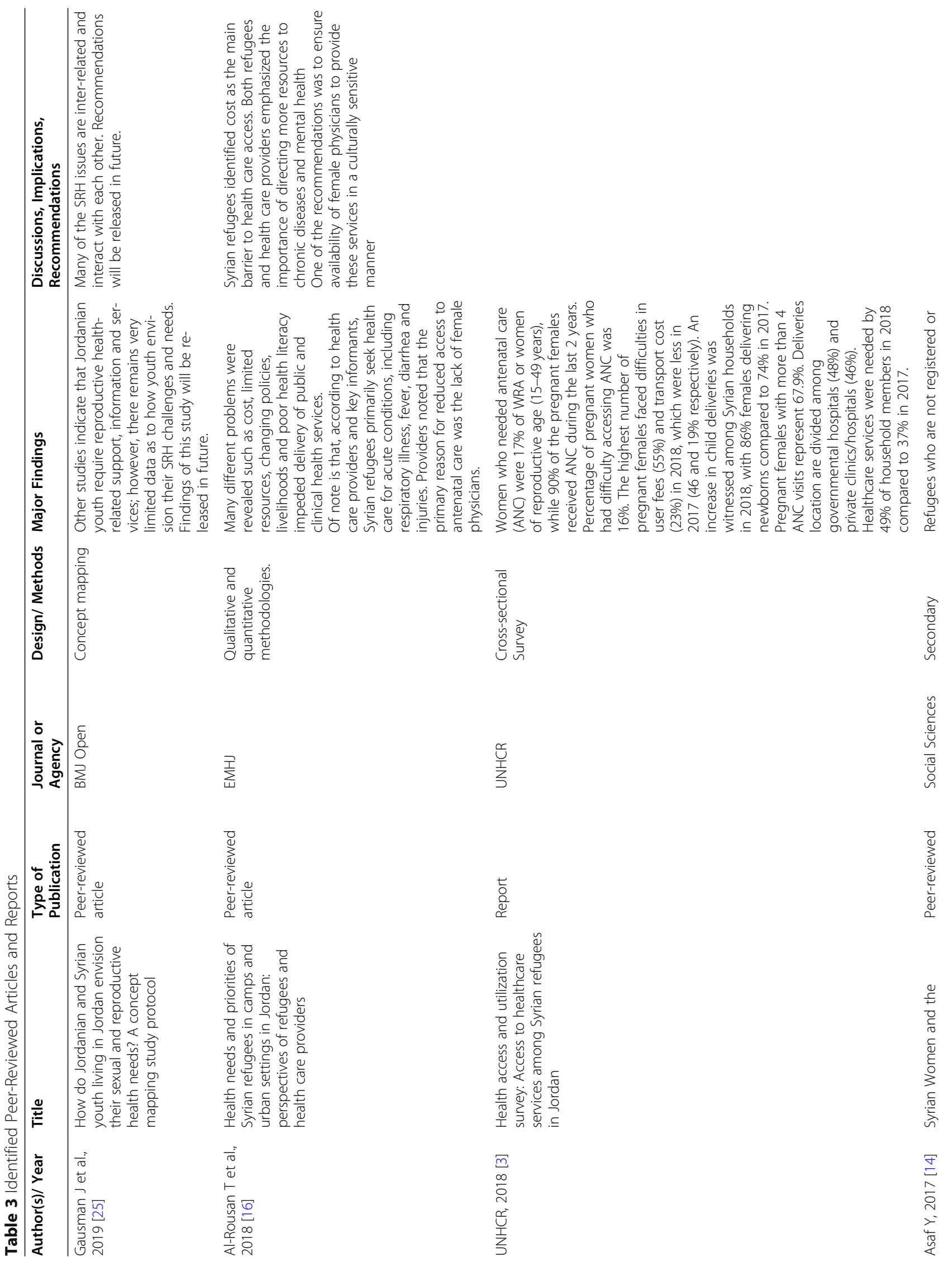




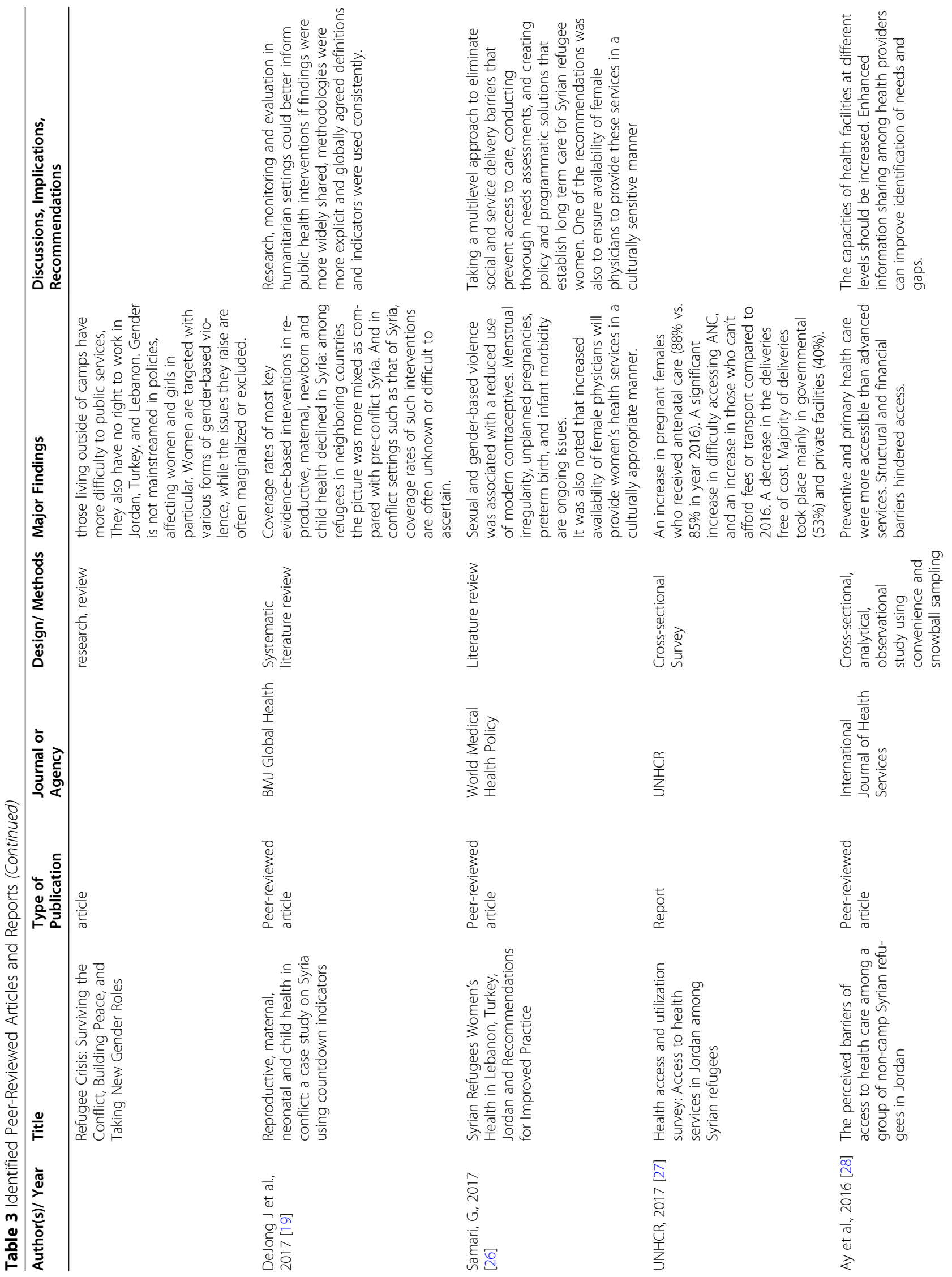




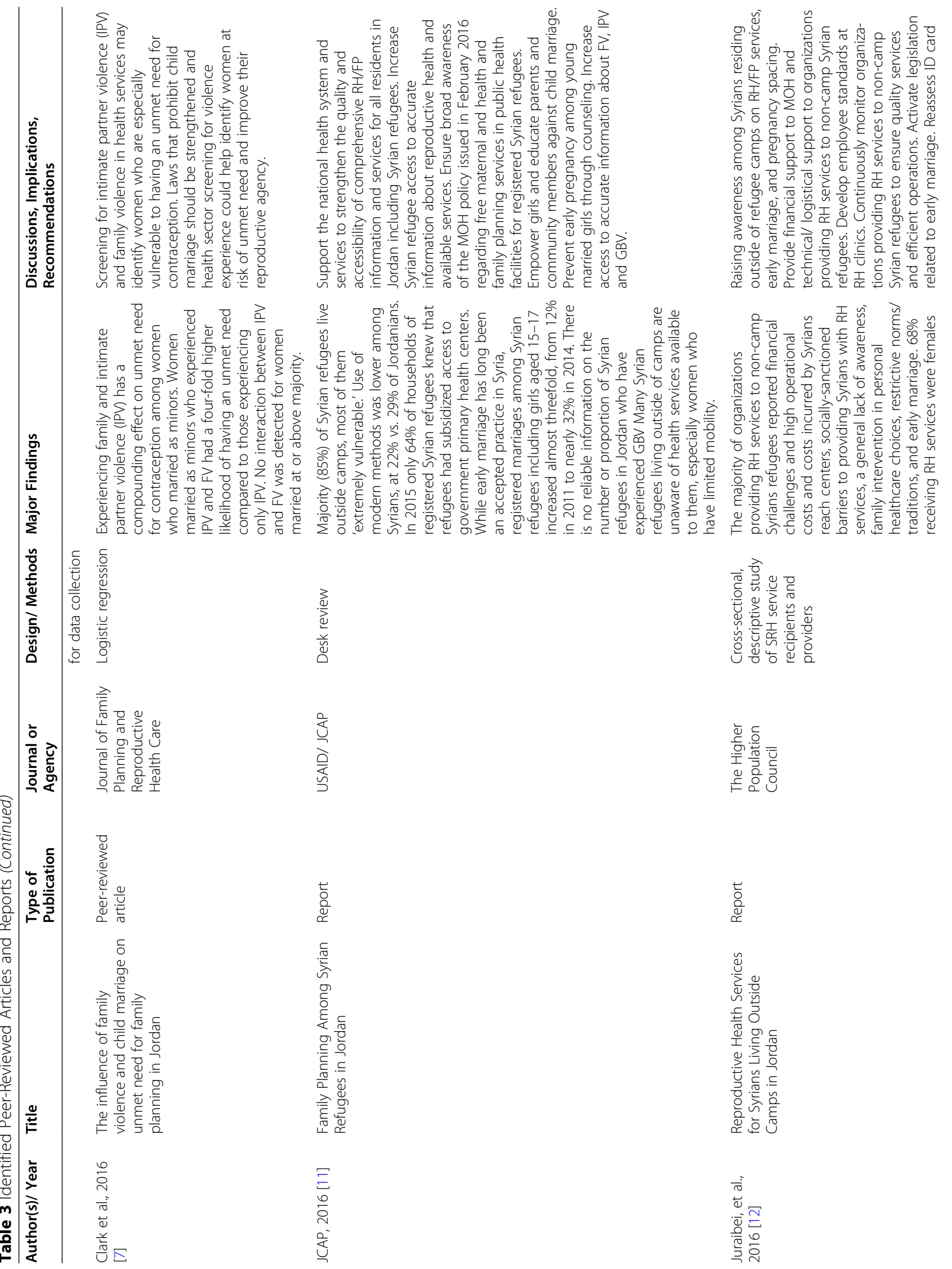




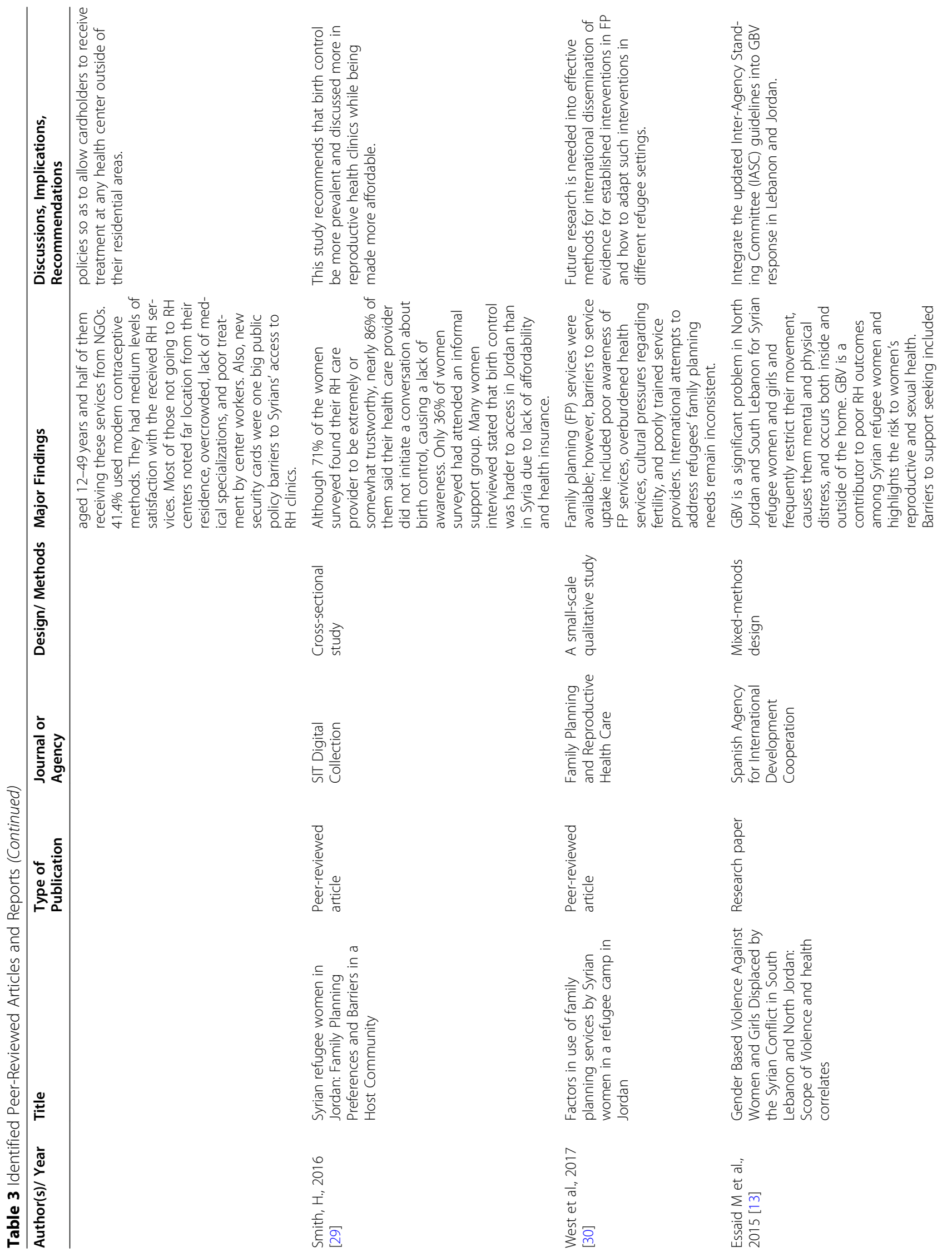




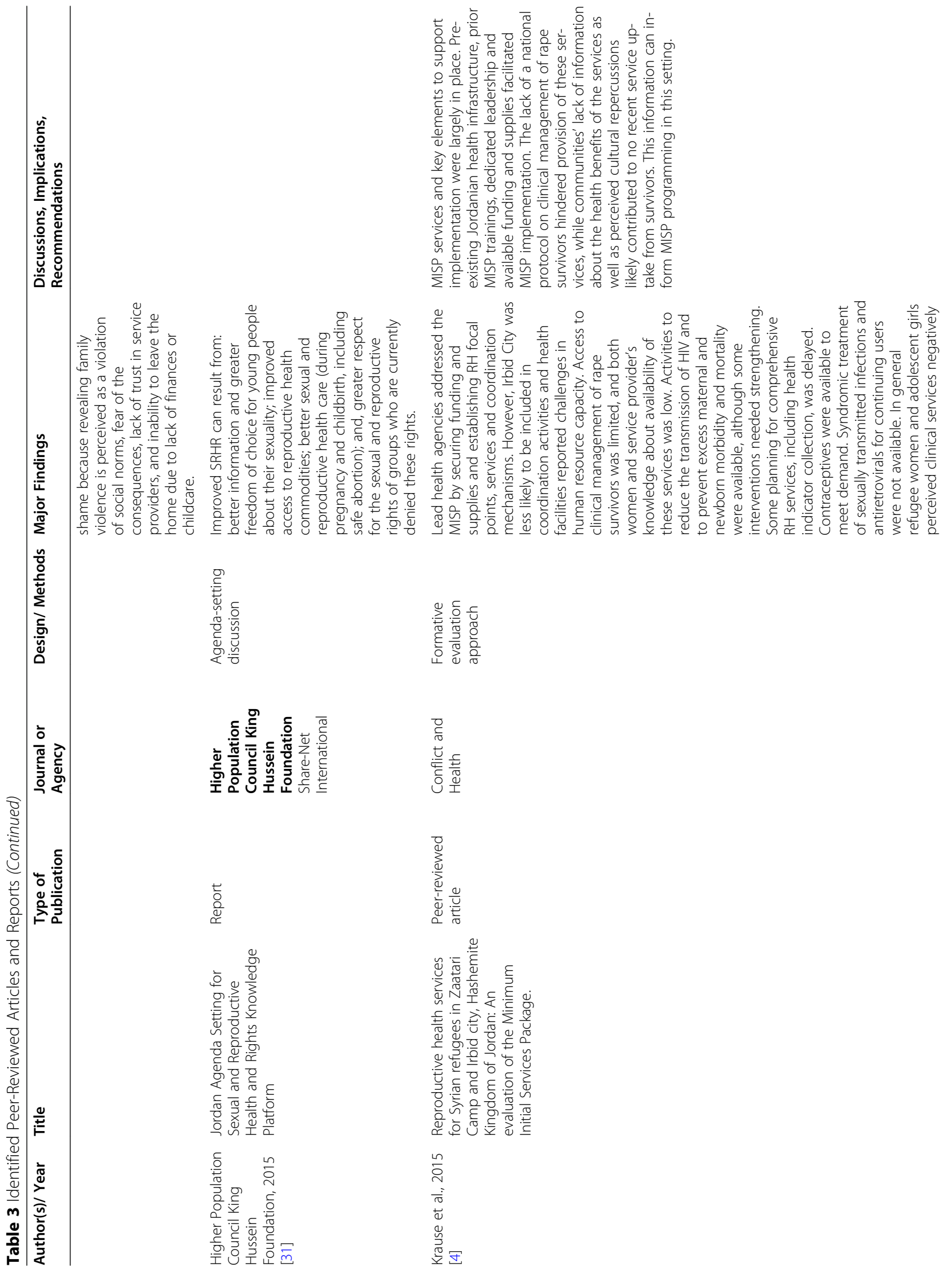




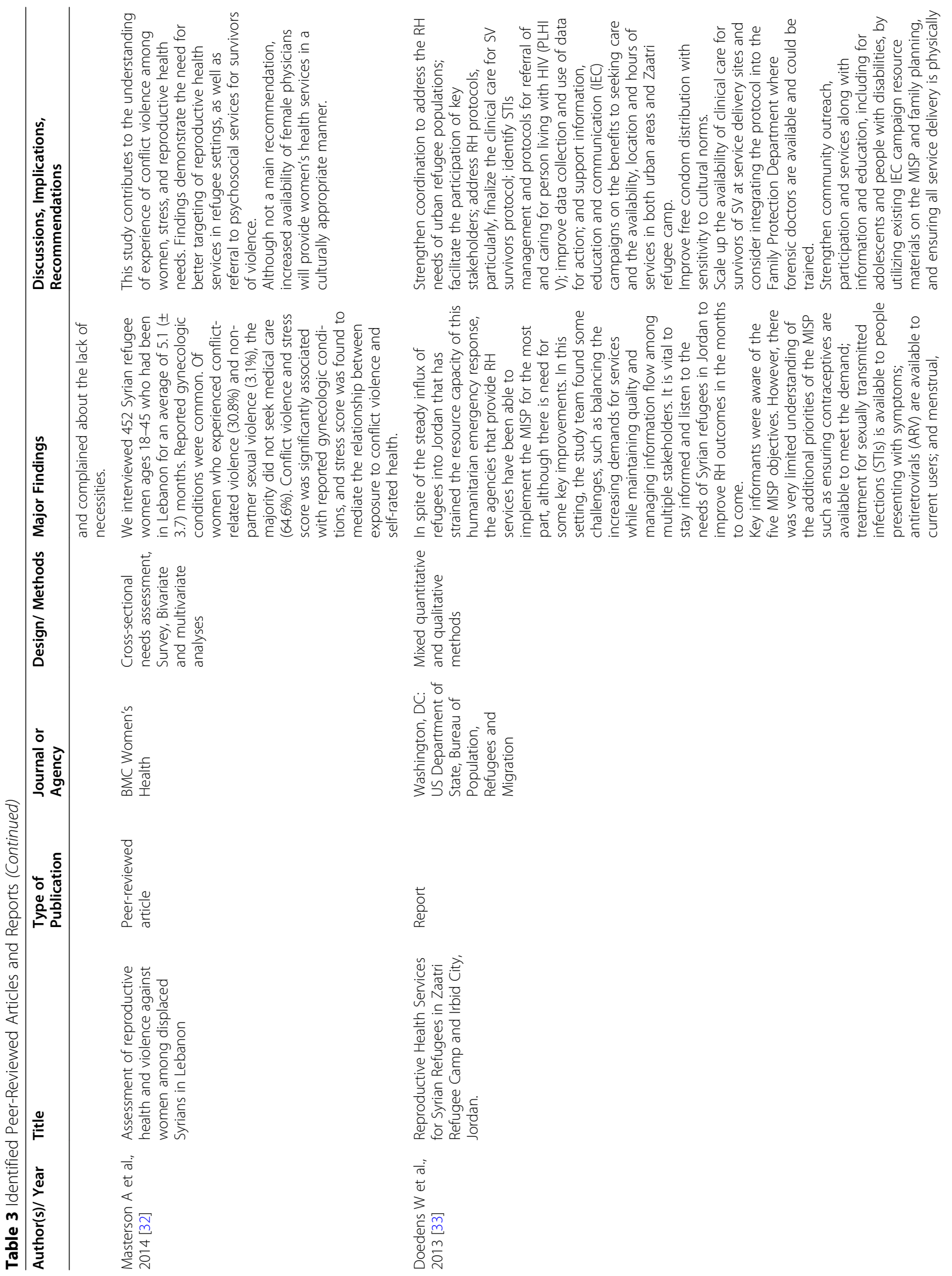




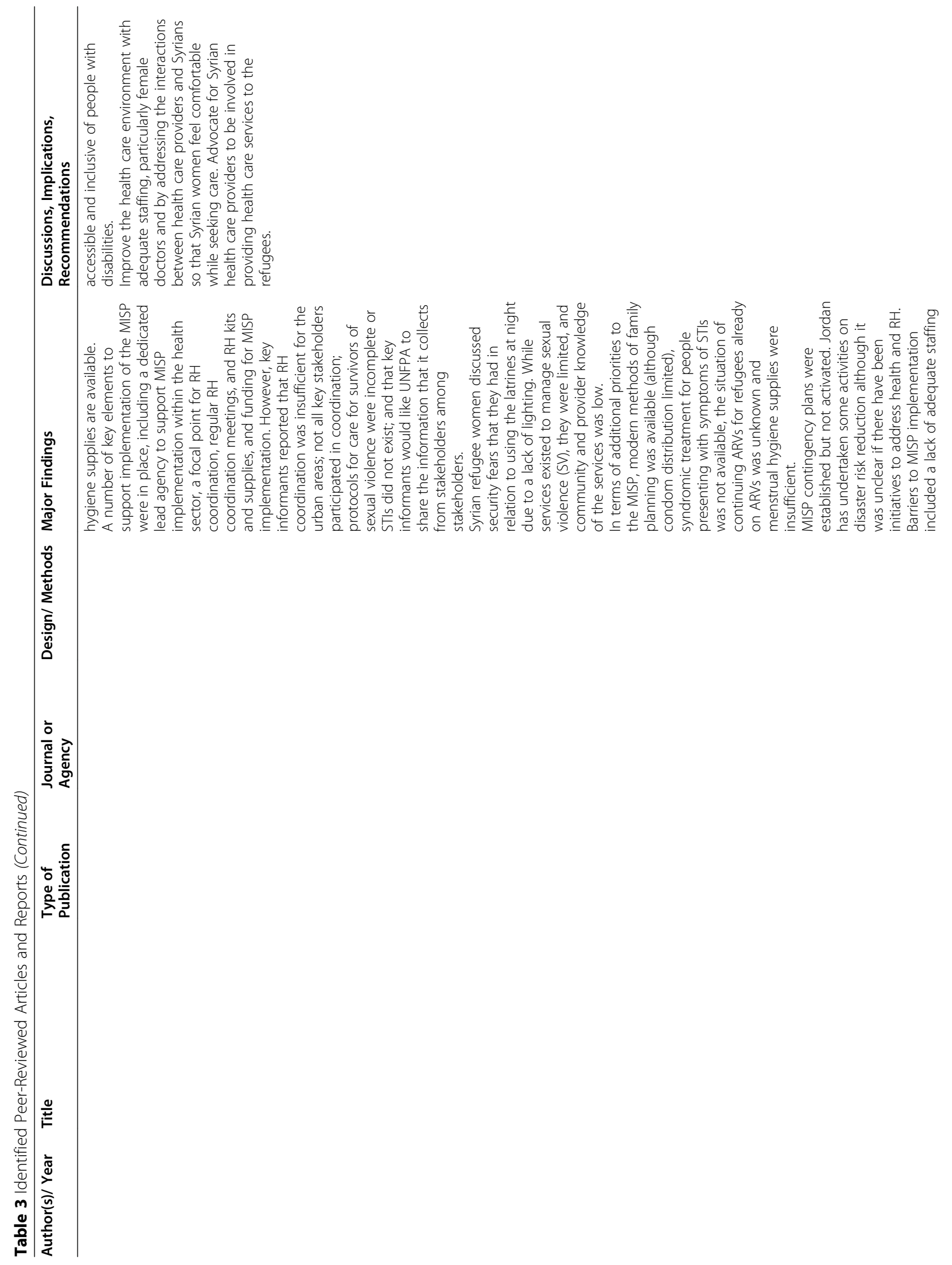




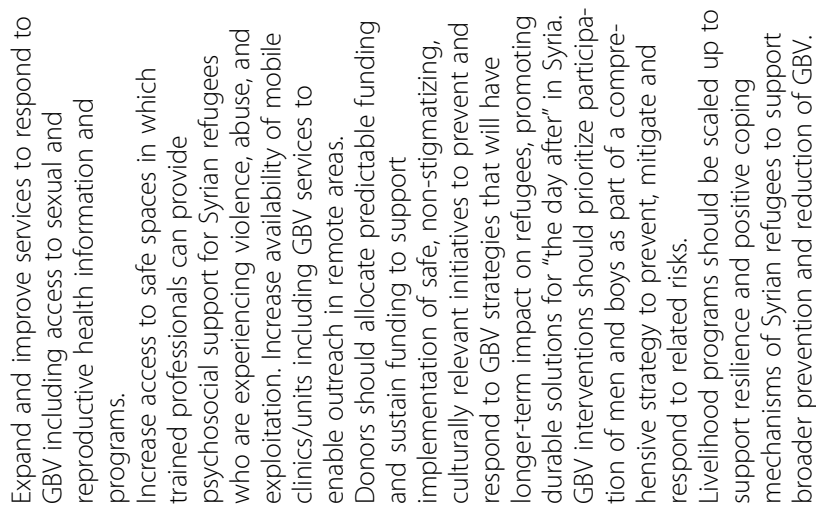

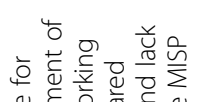

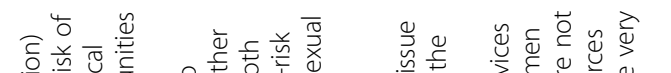

중

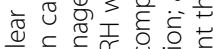

类 ᄃ

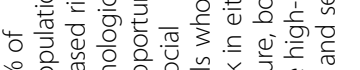

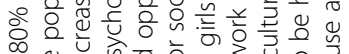

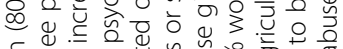

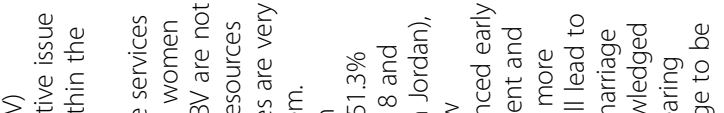

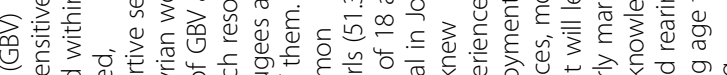

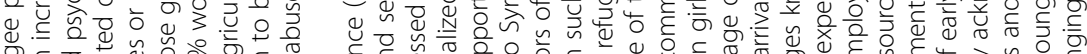

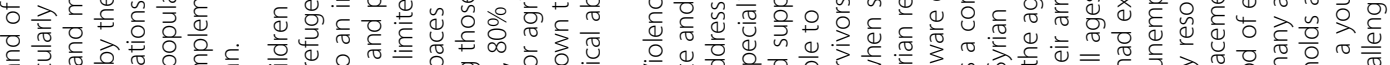

n

它

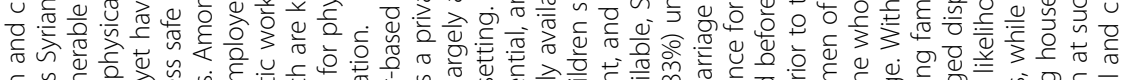
ज绾

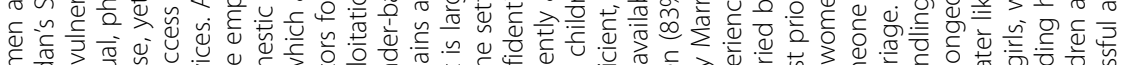

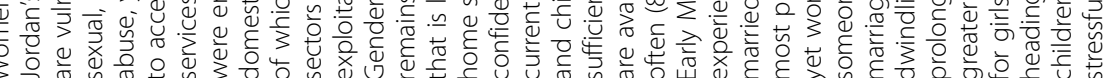

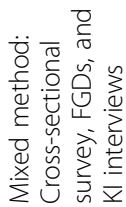

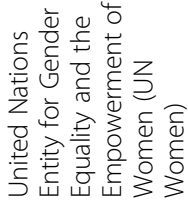
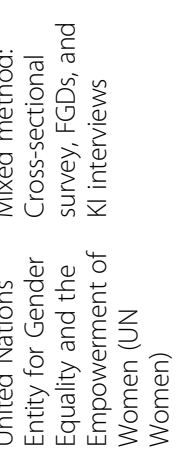

$\frac{5}{0}$
$\stackrel{0}{\dddot{O}}$

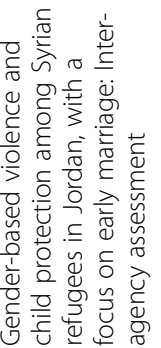

हैं 


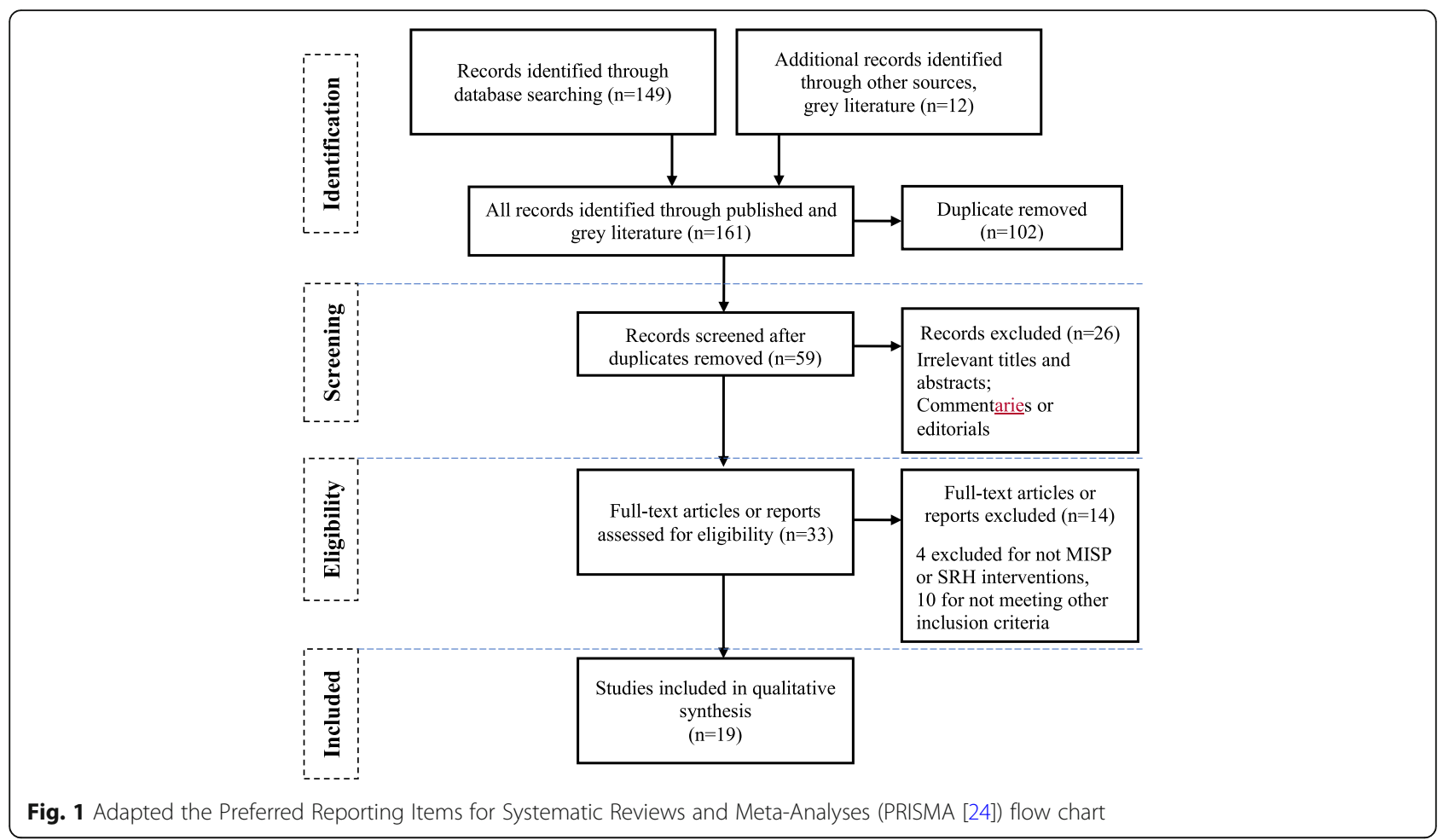

settings, health outcomes, MISP intervention description, key findings and recommendations.

\section{Results}

Out of 19 studies included in our review, 11 were peerreviewed articles and 8 were reports or other types of research papers. Although, the literature review focused on all publications between 2011 and 2019, all studies that met the inclusion criteria were conducted and published post-2013.

In line with the MISP objectives, we, here in discuss the overall results of this review as per the following key areas: RH coordination, barriers to MISP/SRH services (which also covers MISP implementation), gender-based violence and sexual violence, maternal health services, family planning, and HIV/STI prevention (See Table 3).

\section{Coordination of RH services}

The results show that although all studies and reports found eligible for this review discussed certain SRH services, only three peer-reviewed articles $[4,26,30]$ and two reports [29, 33] discussed MISP as a package with focus on selected MISP objectives. In addition, one 2013 study in the form of a report [33], which was also published in 2015 [4], focused on evaluating MISP delivery in both camp and non-camp settings. This study examined agencies providing RH services, it showed that although many of these agencies were able to implement the MISP, key improvements were still needed. It was noted that funding, supplies, and RH lead focal points responsible for services' provision and coordination mechanisms were institutionalized mainly in camp settings, while it was more problematic for set up in noncamp/urban areas. Many factors were attributed to this, including the limitations of effective coordination activities, growing health needs vis a vis the limited human resource capacities. Important areas that were commonly neglected and more challenging included: access to clinical management of rape survivors coupled with limited women's and service providers' knowledge about availability of these services, activities to reduce the transmission of HIV and to prevent excess maternal and newborn morbidity and mortality (while available required more strengthening), and finally planning for effective transition to comprehensive $\mathrm{RH}$ services. Contraceptives were available to meet demand, while syndromic treatment of sexually transmitted infections and antiretrovirals for continuing users were not available.

In general, based on the results of this review, Syrian refugee women and adolescent girls perceived clinical services negatively and complained about the lack of necessities. Barriers to MISP implementation included a lack of adequate staffing in urban areas and of clear $\mathrm{RH}$ protocols, particularly on care for survivors of sexual violence, and management of STIs; less focus by the RH working on urban populations compared with the camp population; and lack of capacity to implement the MISP 
contingency plan [4, 33]. Assessments of MISP have indicated mixed success with gaps in implementation, poor overall coordination, lack of donor support, lack of procedures in place, poor quality and availability of referral services, and inadequate monitoring of service delivery, lack of trained staff to prevent maternal morbidity and mortality, sexual violence, and HIV [4, 26, 29], and a lack of female staff acting as a barrier to FP access for Syrians $[4,30]$. Coordination issues have been addressed in meetings hosted in Amman, but many of the solutions to improve coordination have been focused on Za'atari refugee camp as opposed for these refugees who are dispersed throughout the host communities and who make up the majority of this population $[4,29]$.

\section{Barriers to MISP/SRH services}

Five peer-reviewed articles $[4,16,26,28,29]$ and six reports [3, 11, 12, 27, 31, 33] discussed Syrian refuges access to health facilities and services in general and SRH services in particular.

A number of problems were highlighted including cost, limited resources, changing policies, livelihoods and poor health literacy. These barriers impeded delivery of public and clinical health services in both in-camp and urban settings. Syrian refugees identified cost as the main barrier to health care access [16, 29, 31]. For example, among pregnant Syrian women refugees in 2018, cost of services was reported as the leading cause limiting their access to services (reported by 55\%), this was followed by incurred transportation cost (reported by $23 \%)$. These costs complaints were also reported in 2017 , as $46 \%$ mentioned service costs and 19\% mentioned transportation costs as barrier to access SRH services [3, 27]. For non-camp refugees, preventive and primary health care were more accessible than advanced/tertiary care services and structural and financial barriers hindered access [28]. Specialized, confidential, and counseling and other support services available to Syrian women and children survivors of SGBV (Sexual and Gender-based Violence) were not sufficient, andwhen available-Syrian refugees were very often (83\%) unaware of them [10]. According to one study in 2015, only $64 \%$ of households of registered Syrian refugees knew that refugees had subsidized access to government primary health centers [11]. In one qualitative study, focus group participants indicated that the new security cards were one of the recent greatest imposed public policy restrictions preventing Syrians' access to RH clinics [12].

Refugees who are not eligible to receive primary health care mainly resort to private sectors, which are often perceived by them as highly expensive and unaffordable. A similar trend is observed when it comes to seek medication access, only $10 \%$ of Syrian refugees refer to pharmacies as compared to $18 \%$ who depend on international NGOs institutions as a source of health care and medication use [34].

\section{Sexual and Gender-Based Violence (SGBV)}

Five peer-reviewed articles [7, 14, 26, 32, 33] and five reports $[10-13,33]$ discussed issues surrounding genderbased violence (GBV) and sexual violence (SV).

Limited reliable information exists on the numbers or proportions of Syrian refugees in Jordan who have experienced SGBV. However, it is widely acknowledged, in most of the above-cited sources, that the conflict in Syria and the displacement of Syrians to Jordan has exposed women and children to increased risk of SGBV, abuse, neglect, exploitation and other forms of violence (including early and forced marriage). Women face various forms of violence and they are often marginalized or not effectively assisted (by family, friends, and/or health-care providers) to seek the needed care. The cultural belief system act as one of the main barriers preventing for example adolescents, who experience early marriage and transactional sex, to seek help when needed [13]. As seeking help will further increase the risks of imposed violence often leading to catastrophic consequences such as leading to becoming disowned by their family members or to exposing them to even worse acts such as "honor killing" [4, 13, 33].

One study reported SGBV to be a significant problem among Syrian refugees who are residing in either North Jordan or South Lebanon [13]. These Syrian refugee women and girls are compounded by their inability to seek help for SGBV because of severe restrictions on their movement. Their inability to seek the needed help is often exposing them to mental and physical distress. Barriers observed to seek help or support included: shame because revealing family violence is perceived as a violation of social norms, fear of the consequences, lack of trust in service providers, and inability to leave the home due to lack of finances or childcare [13]. Another study on women refugees, who experienced conflict-related violence $(30.8 \%)$ and non-partner sexual violence $(3.1 \%)$, found that the majority did not seek medical care (64.6\%) [32]. Thus, SGBV remains a private and sensitive issue that is largely addressed within the home setting. Access to clinical management of rape survivors was limited, and both women and service providers' knowledge about availability of such services was low $[4,33]$. Also, specialized, confidential, and supportive services available to Syrian women and children survivors of SGBV are not sufficient, and Syrian refugees are generally unaware of services available for SGBV.

Early marriage has been frequently registered among Syrian refugees in Jordan since the crisis. According to the report by the Jordan Communication, Advocacy and 
Policy Activity (JCAP) project, although child marriage (between 15 and 17) is a generally accepted practice in Syria, rates of registered child marriages among Syrian refugees for girls aged 15-17 has increased by almost threefold in Jordan, from 12\% in 2011 to nearly 32\% in 2014 [11, 12]. According to earlier data from Syria prior to the crisis, it is estimated that around $51.3 \%$ of young girls married before the age of 18, i.e. prior to refuge into Jordan. Moreover, women of all ages knew someone who had experienced early marriage. The report indicates factor contributing to these increased rates are associated with unemployment and dwindling family resources as well as prolonged displacement [10]. Syrian women refugees who are unaccompanied by a male family member often marry their daughters as young as 13 or 15 years of age, as they perceive that this could protect them from being assaulted and/or facing hardships including financial hardships; they believe this will provide with 'roof over their heads'. Further, it is estimated that around $48 \%$ of these girls have been married off to men at least 10 years older. This often increases the vulnerabilities of these young girls to domestic abuse, poverty, and health problems [14].

SGBV poses significant SRH impacts, as it is directly associated with poorer SRH outcomes among Syrian refugee women. One review found that sexual and gender-based violence was associated with a reduced use of modern contraceptives [26]. Similarly, evidence from another study showed that experiencing family violence (FV) and intimate partner violence (IPV) had a compounding effect on unmet need for contraception among women who were married as minors. Women married as minors (child marriage) who experienced IPV and FV had a four-fold higher likelihood of having an unmet family planning needs compared to those experiencing only IPV. No interaction between IPV and FV was detected for women married at or above majority [7]. This study used logistic regression to test whether IPV and FV were independently associated with unmet need by age at marriage.

Moreover, in Jordan, management of the consequences of sexual violence was found of limited quality. Clinical protocols of care informing practitioners on how to best manage survivors of sexual violence were either lacking or incomplete [33].

This is also true for access to emergency contraception (EC) [11]. Although MOH and UNFPA have increased their efforts to improve clinical care for sexual assault survivors as well as IPV survivors through the distribution of clinical management of rape (CMR) kits to health clinics; these seem to not be used effectively as providers' knowledge continues to be limited [11]. One study conducted in 2013 among Syrian refugees in camps found evidence of both severe supply and demand side barriers for EC and CMR. These included: providers' biases in offering women contraception, limited knowledge among women of where to obtain SRH services, providers' refusal to provide emergency contraception post-rape, increased rates of reported unsafe self-induced abortion. Along these lines, it has been reported that providers tend to refuse to give emergency contraception to a rape survivor and/or an unmarried woman $[4,33]$.

\section{Maternal health services}

Three published studies [4, 19, 32] and one report [33] discussed maternal health services, while two reports by UNHCR [3, 27] discussed antenatal care in particular.

According to earlier assessments, activities to prevent excess maternal and newborn morbidity and mortality were available, although some interventions needed strengthening $[4,33]$. According to UNHCR Health Access and Utilization Surveys in Jordan in 2017 and 2018, it has been estimated that $17 \%$ of Syrian females in reproductive age (15-49 years) needed ANC, of which $90 \%$ of them received this care. The percentage of the pregnant women who had difficulty accessing ANC was $16 \%$. The immediate barriers to accessing care included the increased cost of use (55\%) and transport cost (23\%) in 2018, which were less in 2017 (46 and 19\% respectively). Only $67.9 \%$ of pregnant females had 4 or more ANC visits during the course of their pregnancy. Women delivered in either governmental hospitals $(48 \%)$ or private clinics/hospitals (46\%) [3, 27]. ANC coverage among Syrian refugees (at least one ANC visit) in Jordan remains at similar levels to that during the pre-conflict Syria (87.7\%), whereas use of at least four ANC visits has substantially dropped, especially among the non-camp Syrian refugee population. The most reported reason for this lower use was attributed to the limited availability of female physicians [16]. Within the camps in Jordan, several specialized RH facilities have been established; for this reason, postnatal care is often higher (around 50\%) compared to the rates during the pre-conflict Syria. Increases in $\mathrm{C}$-section rates among refugees is not prevailing practice since the conflict began. Rates of skilled birth attendance at delivery among the Syrian refugee population living in camps remain almost universal likely as a result of special provisions by UNHCR [19].

\section{Family planning}

In addition to five eligible reports discussing family planning services coverage $[3,11,12,27,33]$, nine peerreviewed articles $[4,7,13,19,26,28,29,32,35]$ examined family planning. These studies $(n=14)$ mainly examined the extent of family planning knowledge and use with specific focus on contraceptive utilization, service delivery and uptake among Syrian refugees in Jordan. 
The overall findings of these studies suggested that adequate family planning services are available in Jordan for Syrian refugees; yet, significant misconceptions prevail among users pertaining to the different contraceptive methods. A study conducted by UN Women [10] highlighted that this was especially true of child brides where these girls are under extreme pressure to prove their fertility. Among the common misconceptions in the community, which was perpetuated by physicians, is that IUD cannot be inserted until the girl or woman has had at least 2-3 pregnancies. Also, many girls reported overarching fears that using different forms of contraceptives could potentially lead to infertility, this was especially cited when asked about oral contraceptive pills [36]. According to one study in Al-Za'atari camp, it was found that women and girls often lack awareness and knowledge of the different family planning methods and their side effects [4]. Of the reported sides effects among women pertaining to use of family planning were anger, weight gain and the pill "weighing on their bodies". Women of these cited misconceptions around family planning were often found to have lower levels of awareness and knowledge about prevailing workshops/support groups held for females in their communities [33]. One study in 2016 found that family and intimate partner violence (IPV) was associated with compounding effect on unmet need for contraception among women who were married as minors. This study showed that women married as minors who experienced IPV and FV had a four-fold higher likelihood of having an unmet family planning needs compared to those experiencing only IPV [7].

\section{HIV and STI prevention}

Of the eligible included literature in this review, two articles [4, 26] and one report [33] discussed issues related to HIV and STI prevention. These papers mainly indicated inadequate STI and HIV services provided to Syrian women refugees. Other highlights included limited knowledge of the Syrian women refugees on how to reduce HIV transmission. Women associated the notion that HIV would lead to AIDS; however, their knowledge of HIV transmission methods, treatments and lifespan were very poor. The women believed that contracting HIV from blood banks was the main source of transmission as opposed to that from sexual intercourse. It was also indicated that clinics in Amman had limited resources to provide post-exposure treatments. Although male condoms were available in both clinics and in the safe female places, female condoms were neither stocked nor available. Further, health care providers were less likely to provide condoms to unmarried women. This was perceived to increase the risk of contracting HIV and other potential STIs among these refugee women population. Equally important to note is that Syrian refugees who are HIV positive are at higher risk of getting deported, which further limits the availability of HIV testing treatment among Syrian refugees in Jordan $[4,26,33]$.

\section{Discussion}

This, to our knowledge, is the first systematic review summarizing the evidence of the provision of the MISP in the humanitarian context of Jordan. Our review suggests that although Jordan has witnessed significant improvements in the national provision of SRH services for its population, there still remain gaps in the SRH service delivery for Syrian refugees in Jordan $[11,28]$. The findings from our review suggest that Syrian refugee women and girls experience a wide array of barriers in accessing SRH services, including, but not limited, to limited autonomy, mobility, geographical distance, knowledge, cost and social standing [11]. We identified no studies that evaluated the utilization of interventions focused on STI and HIV treatment and prevention, post-abortion and safe abortion care.

To our knowledge, no data exists on the experiences of Syrian refugee women with HIV, which is understandable, as being HIV positive can lead to deportation from Jordan [26, 33]. Such policies are also leading to lack of limited HIV testing and treatment for Syrian refugees who are at risk of or suffering from HIV in Jordan. Thus, unmet SRH needs constitute a significant problem among Syrian women and adolescent refugees in Jordan. Syrian women and girls in Jordan also lack the adequate knowledge and tools to address their needs. As a result, huge misconceptions around FP services, FP needs, and birth spacing exist among this vulnerable population. Except for one study in 2013, that indicated many supply and demand side barriers to emergency contraception (EC) [33], no data exist on availability and use of EC among Syrian refugee women in Jordan. Furthermore, there is limited data on the overall use/ uptake rates of RH services, antenatal care, STI treatment, HIV treatment, psycho-social services, and SGBV treatment to Syrian refugees residing outside camps.

This is of grave concern, given the increased vulnerability of these displaced women and girls on one hand and the inability to inform policies on their actual needs. This affects the availability and quality of provided SRH services. The findings of this review necessitate the need for more responsive health clinics. Additionally, there is a call for international organizations and national NGOs to better deliver on the MISP objectives for the prevention of HIV transmission, by improving the delivery of HIV treatments, comprehensively managing sexual violence, as well exerting better efforts in the delivery of FP 
services and especially EC. More efforts are also needed to reduce maternal mortality/morbidity by addressing the huge disparities often complicating access to antenatal care for non-camp-based settings where these refugee women reside.

Based on the results, the provision and quality of SRH services provided to Syrian refugees in Jordan need to be improved. Additionally, serious efforts need to be made to enable a comprehensive delivery of SRH services, especially to women residing in non-camp-based settings and poor urban settlements. The few studies that addressed MISP interventions showed that MISP objectives were not equally implemented across the different governorates in Jordan where the refugee population cluster most. Also, effective coordination of SRH services poses real challenges to service providers. For example, SRH service providers may experience life threats associated with stigma and cultural taboos about reproductive and sexual health; they may also experience legal and policy constraints related to the age and marital status of individuals seeking SRH services. Moreover, lack of human resources capacity, sustainable training programs, knowledge about SRH services represented equally important impediments that require immediate attention [4].

Finally, this review provided a contextual understanding of the status of the MISP implementation by governmental, local and international agencies in Jordan. It also provided a thoughtful recognition of the Syrian women/ girls' knowledge and attitudes towards SRH.

\section{Limitations}

The authors of this paper have identified multiple limitations to this systematic review. One of them is lack of bibliographic database on non-published reports from civil societies and non-governmental organizations. This may imply that studies conducted by these organizations were missed. Similarly, studies about SRH interventions that did not explicitly refer to the MISP and SRH interventions in the key words, title, or abstract may not have been identified. The search may have also missed titles and abstracts in languages other than English. Screening by two team members may have resulted in varied application of the criteria; however, since the two team members shared the same location, this enabled constant discussion and comparison between them and allowed for a $98 \%$ inter-rater reliability. The cross-sectoral nature of the interventions conducted with different aims, navigating these aims through barriers within country laws, practices and standards, restricted synthesis, different population studies (camp based and urban-based refugees) and study designs lacked comparative data for the most part. Overall, there was a general oversight on the discussion about laws in Jordan impacting the implementation of the MISP for Syrian refugees. Inclusion of grey literature resulted in inclusion of many selfreported data by agencies, which might imply high risk of bias. Limited data was available on the current state of MISP implementation in Jordan almost 9 years post crisis.

It should also be noted that many of the aforementioned limitations are to be expected, given the nature of humanitarian-context, where often conducting a thorough research is crippled given the many context challenges as well as the inherent vulnerabilities of displaced women and girls as a result of fear, stigma and the need for secrecy [37]. The authors, however, believe this review helps in providing a comprehensive overview of the existent barriers to SRH use and service delivery in Jordan 9 years into the crisis. It also guides in providing evidence-based recommendations.

\section{Conclusions}

The MISP is a set of priority activities and services that are recognized as standard care for SRH in emergency and humanitarian settings. Since the beginning of the Syrian crisis, the influx of the Syrian refugee population into Jordan increased rapidly over the years. Hence, information and data on the needs and challenges of this population is rapidly becoming outdated and requires regular monitoring. Any SRH program must integrate the needs of Syrian refugees residing within host communities in addition to those living in camps. Despite the significant progress in the MISP policies and the review of the IAFM guidelines in 2018 at a global level, there remains gaps in the overall availability and utilization of the different MISP and SRH service delivery in Jordan.

Furthermore, this review spotted the light on the limited research conducted around MISP implementation and its delivery in Jordan. In fact, only one study by Doedens et al., that was conducted in 2013 [33] and then published in 2015 [4], evaluated the implementation of the MISP objectives, effectiveness of the coordination mechanisms, and training on the mentioned package in Jordan. Most of the available literature discussing MISP cited one or both of these two sources. Hence, to be able to inform national SRH guidelines and policies in Jordan for improved SRH service delivery to respond to the needs of this refugee population without compromising the needs of the general Jordanian population, more implementation research is needed to identify barriers and challenges as well as inform evidence-based strategies to improve Syrian refugees' access to SRH services.

\section{Abbreviations}

AIDS: Acquired Immune Deficiency Syndrome; ANC: Ante-Natal Care;

ART: Anti-Retroviral Therapy; ARV: Anti-Retroviral; BEmONC: Basic obstetric and newborn complications; BMC: Bio-Med Central; BMJ: British Medical Journal; CEmONC: Comprehensive Emergency Obstetric and Newborn Care; 
CMR: Clinical Management of Rape; EC: Emergency Contraception; EMHJ: Eastern Mediterranean Health Journal; EmONC: Emergency obstetric and Newborn Care; FGD: Focus Group Discussion; FP: Family Planning; FV: Family Violence; GBV: Gender-Based Violence; HIV: Human Immunodeficiency Virus; IEC: Information Education and Communication; IPV: Intimate Partner Violence; IUD: Intra-Uterine Device; JCAP: Jordan Communication Advocacy and Policy activity; Kl: Key Informant; MISP: Minimum Initial Service Package; MoH: Ministry of Health; NGO: NonGovernmental Organizations; PEP: Post-exposure prophylaxis; PRIS MA: Preferred Reporting Items for Systematic Reviews and Meta-Analyses; PMTCT: Prevention of mother-to-child transmission; RH: Reproductive Health; SDGs: Sustainable Development Goals; SGBV: Sexual and Gender Based Violence; SRH: Sexual and Reproductive Health; STI: Sexual Transmitted Infections; SV: Sexual Violence; UN: United Nations; UNFPA: United Nations Population Fund; UNHCR: United Nations High Commissioner for Refugees; USAID: United States Agency for International Development

\section{Acknowledgements}

Not applicable.

\section{Authors' contributions}

Each author listed on the title page of this paper have made substantial contributions to the conception (authors \#1, 2, and 5) AND/OR design of the work $(\# 1,2) ; A N D / O R$ independent extraction and analysis of data from published papers (\#1, 2); AND/OR the acquisition, analysis, AND/OR interpretation of results (authors\#1-5); AND/OR have drafted the work or substantively revised it (authors\#1-5). Additionally, all authors have approved the submitted version (and any substantially modified version that involves the author's contribution to the study); AND have agreed both to be personally accountable for their own contributions and to ensure that questions related to the accuracy or integrity of any part of the work, even ones in which the author was not personally involved, are appropriately investigated, resolved, and the resolution documented in the literature. The first author also served as the corresponding author for this work.

\section{Funding}

This work was funded by the Department of Reproductive Health and Research (RHR), including the UNDP/UNFPA/UNICEF/WHO/World/Bank Special programme of research, development and research training in human reproduction (HRP). The funders had no role in study design, data collection and analysis, decision to publish, or preparation of the manuscript.

\section{Availability of data and materials}

All data generated or analyzed during this study are included in this published article and/or its supplementary information files.

\section{Ethics approval and consent to participate}

Not applicable. As this review did not constitute any human subject research, ethics approval and consent were not required.

\section{Consent for publication}

Not applicable.

\section{Competing interests}

The authors declare that they have no competing interests. The authors alone are responsible for the views expressed in this article and they do not necessarily represent the views, decisions or policies of the funding bodies or institutions with which they are affiliated.

\section{Author details}

'The Eastern Mediterranean Public Health Network (EMPHNET), Shmeisani, Abdallah Ben Abbas Street, Bldg No. 42, Amman, Jordan. ${ }^{2}$ Faculty of Health Sciences, The University of Ottawa, 75 Laurier Ave E, Ottawa, ON K1N 6N5, Canada. ${ }^{3}$ World Health Organization, 20 Avenue Appia, 1211, Geneva 27. Switzerland.
Received: 28 December 2019 Accepted: 4 October 2020

Published online: 28 October 2020

\section{References}

1. UNHCR. UNHCR Syria Regional Refugee Response 2019: United Nations High Commission for Refugees; 2019. Available from: https://data2.unhcr. org/en/situations/syria. [cited 2019 Apr 25].

2. ILO. Access to work for Syrian refugees in Jordan: a discussion paper on labor and refugee laws and policies. 2015. Available from: https://www.lo. org/wcmsp5/groups/public/\%2D\%2D-arabstates/\%2D\%2D-ro-beirut/ documents/publication/wcms_357950.pdf.

3. UNHCR. Health access and utilization survey: access to healthcare services among Syrian refugees in Jordan. 2018. Available from: https://data2.unhcr. org/en/documents/details/68539.

4. Krause S, Williams H, Onyango MA, Sami S, Doedens W, Giga N, et al. Reproductive health services for Syrian refugees in Zaatri Camp and Irbid City, Hashemite Kingdom of Jordan: an evaluation of the Minimum Initial Services Package. Confl Health. 2015;9(Suppl 1):S4 Available from: http:// conflictandhealth.biomedcentral.com/articles/10.1186/1752-1505-9-S1-S4. [cited 2019 Mar 24].

5. UNHCR \& Swedish International Development Cooperation Agency. Assessing the Needs of Refugees for Financial and Non-Financial ServicesJordan Final Report Assessing the needs of refugees for financial and nonfinancial services-Jordan. 2018. Available from: https://data2.unhcr.org/en/ documents/download/66387.

6. Weinstein JN, Geller A, Negussie Y, Baciu A. Communities in action: pathways to health equity. Washington, DC: National Academies Press; 2017. p. 1-558

7. Clark CJ, Spencer RA, Khalaf IA, Gilbert L, El-Bassel N, Silverman JG, et al. The influence of family violence and child marriage on unmet need for family planning in Jordan. J Fam Plan Reprod Heal Care. 2016;43(2):105-12 Available from: https://doi.org/10.1136/fprhc-2014-101122.

8. Department of Statistics (DOS) and ICF. Jordan Population and Family and Health Survey 2017-18. Amman and Rockville: DOS and ICF; 2019. https:// dhsprogram.com/pubs/pdf/FR346/FR346.pdf.

9. Gavlak D. Syrians flee violence and disrupted health services to Jordan, vol. 91: Bulletin of the World Health Organization; 2013. p. 394-5. Available from: http://www.who.int/entity/bulletin/volumes/91/6/13-020613.pdf. [cited 2019 Oct 14].

10. UN Women. Gender-based violence and child protection among Syrian refugees in Jordan, with a focus on early marriage: inter-agency assessment. 2013. Available from: https://jordan.unwomen.org/en/digital-library/ publications/2013/7/gender-based-violence-and-child-protection-amongsyrian-refugees-in-jordan\#view.

11. JCAP. Family Planning among Syrian Refugees in Jordan, March 2016. 2016. Available from: https://jordankmportal.com/resources/family-planningamong-syrian-refugees-in-jordan.

12. Juraibei M. Reproductive Health Services for Syrians Living Outside Camps in Jordan. Amman: Higher Population Council; 2016. Available from: https:// www.hpc.org.jo/sites/default/files/Reproductive Health Services for Syrians Living Outside Camps in Jordan.pdf.

13. Essaid A, Usta J, Shukri H, El-Gharaibeh Y, Abu Taleb H, Awwad N, et al. Gender based violence against women and girls displaced by the Syrian conflict in South Lebanon and North Jordan: scope of violence and health correlates. 2015 Available from: https://www.alianzaporlasolidaridad.org/wpcontent/uploads/GBV-Against-Women-and-Girl-Syrian-Refugees-in-Lebanonand-Jordan-FINAL.pdf.

14. Asaf Y. Syrian Women and the Refugee Crisis: Surviving the Conflict, Building Peace, and Taking New Gender Roles. Soc Sci. 2017;6(3):110 Available from: https://doi.org/10.3390/socsci6030110.

15. Tiltnes $\AA A$, Zhang $\mathrm{H}$, Pedersen J. The living conditions of Syrian refugees in Jordan: results from the 2017-2018 survey of Syrian refugees inside and outside camps. 2019. Available from: https:/reliefweb.int/report/jordan/ living-conditions-syrian-refugees-jordan-results-2017-2018-survey-syrianrefugees.

16. Al Rousan T, Schwabkey Z, Jirmanus L, Nelson BD. Health needs and priorities of Syrian refugees in camps and urban settings in Jordan: perspectives of refugees and health care providers. East Mediterr Heal J. 2018;24(03):243-53 Available from:. https://doi.org/10.26719/2018.24.3.243.

17. UNFPA. Shortage in funding threatens care for pregnant Syrian refugees UNFPA - United Nations Population Fund. 2015. Available from: https:// 
www.unfpa.org/news/shortage-funding-threatens-care-pregnant-syrianrefugees. [cited 2019 Oct 20].

18. UNFPA. Essential health needs of Women often neglected in assistance after natural disasters, conflicts: In United Nations Population Fund; 2015 Available from: https://www.unfpa.org/press/essential-health-needs-womenoften-neglected-assistance-after-natural-disasters-conflicts.

19. DeJong J, Ghattas H, Bashour H, Mourtada R, Akik C, Reese-Masterson A. Reproductive, maternal, neonatal and child health in conflict: a case study on Syria using Countdown indicators. BMJ Glob Heal. 2017;2(3):e000302 Available from: https://doi.org/10.1136/bmjgh-2017-000302.

20. Khan KS, Kunz R, Kleijnen J, Antes G. Five steps to conducting a systematic review. J R Soc Med. 2003;96(3):118-21.

21. United Nations. Report of the international conference on population and development. 1994. Available from: https://www.un.org/en/development/ desa/population/events/pdf/expert/27/SupportingDocuments/A_CONF.1 71_13_Rev.1.pdf.

22. Spangaro J, Adogu C, Ranmuthugala G, Powell Davies G, Steinacker L, Zwi A. What evidence exists for initiatives to reduce risk and incidence of sexual violence in armed conflict and other humanitarian crises? A Systematic Review. PLoS One. 2013;8(5):e62600 Available from: https://doi.org/10.1371/ journal.pone.0062600.

23. IAWG. Inter-agency field manual on reproductive health in humanitarian settings. 2018. Available from: http://iawg.net/resources2013/tools-andguidelines/fieldmanual/.

24. Moher D, Liberati A, Tetzlaff J, Altman DG. Preferred reporting items for systematic reviews and meta-analyses: the PRISMA statement. J Clin Epidemiol. 2009:62(10):1006-12.

25. Gausman J, Othman A, Hamad IL, Dabobe M, Daas I, Langer A. How do Jordanian and Syrian youth living in Jordan envision their sexual and reproductive health needs? A concept mapping study protocol. BMJ Open. 2019;9(1):e027266 Available from. https://doi.org/10.1136/bmjopen-2018027266

26. Samari G. Syrian refugee Women's health in Lebanon, Turkey, and Jordan and recommendations for improved practice. World Med Heal Policy. 2017; 9(2):255-74 Available from: https://doi.org/10.1002/wmh3.231.

27. UNHCR. Health access and utilization survey: access to healthcare services among Syrian refugees in Jordan. 2017. Available from: https://data2.unhcr. org/en/documents/details/62498

28. Ay M, Arcos González P, Castro DR. The perceived barriers of access to health care among a group of non-camp Syrian Refugees in Jordan. Int J Heal Serv. 2016;46(3):566-89 Available from: https://doi.org/10.1177/ 0020731416636831.

29. Smith H. Syrian Refugee Women in Jordan: Family Planning Preferences and Barriers in a Host Community. Independent Study Project (ISP) Collection. 2445. 2016. Available from: https://digitalcollections.sit.edu/isp_ collection/2445

30. West L, Isotta-Day H, Ba-Break M, Morgan R. Factors in use of family planning services by Syrian women in a refugee camp in Jordan. J Fam Plan Reprod Heal Care. 2017:43:96-102.

31. HPC, KHF. Jordan agenda setting for sexual and reproductive health and rights knowledge platform. 2015. Available from: http://sharenetinternational.org/wp-content/uploads/2017/02/Annex-9-Jordan-agendasetting-and-mapping.pdf

32. Reese Masterson A, Usta J, Gupta J, Ettinger AS. Assessment of reproductive health and violence against women among displaced Syrians in Lebanon. BMC Womens Health. 2014;14(1) Available from:. https://doi.org/10.1186/ 1472-6874-14-25.

33. Doedens W, Giga N, Krause S, Onyango MA, Sami S, Stone E, et al. Reproductive health services for Syrian refugees in Zaatari Refugee Camp and Irbid, Jordan. 2013. Available from: https://data2.unhcr.org/en/ documents/download/39302. [cited 2019 Oct 14].

34. Krafft C, Sieverding M, Keo C, Salemi C. Syrian refugees in Jordan: demographics, livelihoods, education and health. 2018. Available from: http://erf.org.eg/publications/syrian-refugees-in-jordan-demographicslivelihoods-education-and-health/.

35. West L, Isotta-Day H, Ba-Break M, Morgan R. Factors in use of family planning services by Syrian women in a refugee camp in Jordan. J Fam Plan Reprod Heal Care. 2016;43(2):96-102 Available from: https://doi.org/10. 1136/jfprhc-2014-101026.

36. Bardaweel SK, Akour AA, AlKhawaldeh A. Impediments to use of oral contraceptives among refugee women in camps, Jordan. Women Health.
2018;59(3):252-65 Available from: https://doi.org/10.1080/03630242.2018 1452837.

37. Stark L, Ager A. A systematic review of prevalence studies of gender-based violence in complex emergencies. Trauma Violence Abus. 2011;12(3):127-34 Available from: https://doi.org/10.1177/1524838011404252.

\section{Publisher's Note}

Springer Nature remains neutral with regard to jurisdictional claims in published maps and institutional affiliations.

\section{Ready to submit your research? Choose BMC and benefit from:}

- fast, convenient online submission

- thorough peer review by experienced researchers in your field

- rapid publication on acceptance

- support for research data, including large and complex data types

- gold Open Access which fosters wider collaboration and increased citations

- maximum visibility for your research: over $100 \mathrm{M}$ website views per year

At $\mathrm{BMC}$, research is always in progress.

Learn more biomedcentral.com/submissions 